\title{
Interactive comment on "A standardized database of Marine Isotopic Stage 5e sea-level proxies on tropical Pacific Islands" by Nadine Hallmann et al.
}

\author{
Nadine Hallmann et al. \\ hallmann@cerege.fr \\ Received and published: 17 December 2020
}

This review paper relies on data that have been produced by various authors since several decades. The section 6.6 details the uncertainties and the data quality concerning the 284 data points that have been used. In this section, we have stressed that the data quality is mostly affected by uncertainties related to RSL data and, to a lesser extent, to age information. Section 7 concerns recommendations for future research in this region, especially regarding better constraints on $\mathrm{RSL}$ data, the establishment of an accurate chronology of LIG reef deposits and the study of their development patterns.

We notice that most of P. Blanchon's comments raise general issues that are beyond the scope of this paper, including the species concept in Scleractinia and eventually 
the use of coral assemblages to deduce palaeo-water depths in the fossil record.

Hybridisation was traditionally considered rare on coral reefs. However, a rapid increase in hybrid studies over the last 20 years has revealed that hybridisation on coral reefs is common and widespread. However, to our knowledge, the impact of such processes on taxonomy of fossil corals has not been evaluated. No reference other than Veron's seminal book is given in P. Blanchon's comment.

In his comment, P. Blanchon questions the use of coral assemblages to reconstruct sea-level change in the fossil record and states that coralgal assemblages must be only used in combination with facies analysis. We disagree with that statement. The composition and distribution of reef assemblages typically reflect environmental parameters such as light conditions, turbidity, water energy and nutrient levels because reef dwelling organisms are sensitive to subtle ecological changes affecting their environment (Camoin and Webster, 2015). Over the two last decades, in situ reef assemblages, including corals and associated biota (i.e., coralline algae, vermetid gastropods and encrusting foraminifera) rather than monospecific coral communities, have increasingly been used to more accurately constrain palaeo-water depths as well as other important palaeo-environmental parameters (see review in Camoin and Webster, 2015). Interpretation of fossil assemblages of corals and associated biota relies on the occurrence, ecology and zonation of modern counterparts, and the presumption that similar factors controlled their distribution. To do that, one does not have to identify at the species level every single member of that fossil assemblage, but only the dominant species or morpho-groups (closely related species with similar morphological characteristics) indicative of a specific modern coral community and reef setting.

In our review of MIS 5e reef deposits from tropical Pacific Islands, data reported in the literature do not include details regarding the composition of reef assemblages and concern coral identification mostly at the genus or family levels. This introduces generally very large RSL uncertainties and excludes any constraint regarding the RSL position during MIS 5e. Our Table 2 summarizes the best estimates of palaeo-water depth 
intervals for corals that were quoted in the literature, based on the OBIS and other databases that list modern counterparts from the whole Indo-Pacific region. With two exceptions, all concerned islands/groups of islands are not characterized by macrotidal ranges.

Facies sequences are also an important component to reconstruct sea-level change and have been considered in parallel to the analysis of reef assemblages in many studies focused on fossil reefs from the Indo-Pacific (see Camoin and Webster, 2015 and references therein). However, it is difficult to assess which additional information related to facies sequences could be obtained from the subsurface of modern reefs compared to their surface, as the vertical growth of modern reefs has been limited since the end of the last deglacial sea-level rise.

"The truth is rarely pure and never simple" (Oscar Wilde)

Interactive comment on Earth Syst. Sci. Data Discuss., https://doi.org/10.5194/essd-2020-261, 2020. 